\title{
Editorial
}

\section{Gamma-glutamyl transferase: risk and prognosis of cancer}

\author{
IS Fentiman*,I \\ 'GKT School of Medicine, Guy's Hospital, London SEI 9RT, UK
}

British Journal of Cancer (2012) 106, |467-|468. doi:I0.1038/bjc.20 I2.128 www.bjcancer.com

(c) 2012 Cancer Research UK

Gamma-glutamyl transferase (GGT) is a membrane-bound enzyme catabolising reduced glutathione to cysteine and glycine in Meister's $\gamma$-glutamyl cycle (Orlowski and Meister, 1970). This delivers cysteine for intracellular synthesis of glutathione, the major thiol anti-oxidant. Elevated serum levels of GGT are markers of oxidative stress, resulting from factors including alcohol, heavy metals, cardiovascular disease and diabetes.

In this issue, an Austrian multicentre study is reported, which shows an association between GGT and prognosis in women with endometrial carcinoma (Seebacher et al, 2012). Gamma-glutamyl transferase levels were evaluated in 874 consecutive patients who were stratified in risk groups. After multivariate analysis, elevated and highly elevated serum GGT levels were independently associated with poorer survival. There was no association with advanced tumour stage, higher tumour grade or with more aggressive histology.

High levels of GGT seem to increase the risk of progression of high-grade cervical dysplasia to invasive carcinoma. Recently, as part of a multi-centre trial, pre-treatment GGT levels were examined in 692 patients with cervical cancer (Polterauer et al, 2011). Gamma-glutamyl transferase serum levels were significantly associated with FIGO stage and age (but not with lymph node involvement $(P=0.85)$, and histological type. There was a linear correlation between GGT and prognosis.

Furthermore, higher serum levels of GGT, within the normal range, are associated with an increased cancer risk. In the Vorarlberg study of 92983 females, there was an increasing hazard rate for various cancers with higher levels of the enzyme (Strasak et al, 2008). Within the Guernsey Cohort Study, a highly significant association was found between levels of GGT and breast cancer risk in premenopausal women (Fentiman and Allen, 2010). These results were confirmed in the Apolipoprotein Mortality Risk (AMORIS) study of 545460 Swedes (Van Hemelrijck et al, 2011). When subdivided by categories of GGT $(<18,18-36,36-72$, $>72 \mathrm{Ul}^{-1}$ ) there was an increasing association with overall cancer risk. For those with glucose levels $>6.11 \mathrm{mmoll}^{-1}$, the association with risk of prostate, breast and liver cancer became stronger, supporting a role for oxidative stress in the process of carcinogenesis.

In the third US National Health and Nutrition Examination Survey (NHANES) blood lead and urinary cadmium levels were measured together with serum GGT in 10098 adults (Lee et al, 2006). After adjustment for race, sex and age, both blood lead and urinary cadmium levels showed graded positive associations, with serum GGT. Subsequently, elevated urinary cadmium levels were shown to be associated with increased breast cancer risk

*Correspondence: Professor IS Fentiman; E-mail: ian.fentiman@gstt.nhs.uk
(Gallagher et al, 2010). This strong association with a marker of oxidative stress in a normal population suggests a possible carcinogenic role for lead and cadmium in individuals with low environmental exposure.

Death certificate-based 12-year mortality was also examined in the third NHANES project in relation to serum alanine aminotransaminase (ALT) and GGT (Ruhl and Everhart, 2009). Elevated ALT was associated with deaths from hepatic disease but not with all-cause mortality. In contrast, elevated GGT was associated with all-cause mortality from liver disease, neoplasms and diabetes.

There is evidence that GGT is dysregulated in malignant cells and by producing reactive oxygen species cause tumour progression towards more aggressive phenotypes associated with a worse prognosis (Dawson et al, 1979, Hanigan et al, 1999). In a study of human GGT-transfected melanoma cells, higher levels of GGT activity were associated with greater levels of background DNA damage and oxidised bases (Corti et al, 2008). This was unrelated to differences in cell cycle distribution or apoptotic rates. Culture of GGT-over-expressing cells with GGT substrates and catalytic iron resulted in further DNA damage, eliminated in the presence of GGT inhibitors such as L-2-amino-4-boronobutanoic acid (ABBA).

Curcumin, a polyphenol extracted from Curcuma longa has anti-tumour effects on ZR-75-1 cells, resistant to oxidative damage (Quiroga et al, 2010). In a dose-dependent manner, it is both cytotoxic and inhibitory to GGT activity. If elevated levels of GGT are marking an increased risk of recurrence of cancer, it is possible that curcumin has therapeutic potential in this situation. Under other circumstances the agent has been shown to be both effective and non-toxic in a randomised double-blind placebo-controlled trial of Iranian war veterans with sulphur mustard-induced pruritus (Panahi et al, 2011).

So, what can be made of this? In terms of carcinogenesis, GGT clearly is a marker of oxidative stress. What is unclear is whether GGT has a direct aetiological role or is an indicator of collateral damage. Another factor to be considered is that GGT is elevated by alcohol consumption, which has a direct role in carcinogenesis for liver, pancreas, larynx and breast. It should, however, be noted that higher levels of GGT within the normal range are associated with increased risk of cancer so that causes other than alcohol may be involved. More basic studies are needed using mice with GGT knockout to determine whether GGT has an aetiological role in carcinogenesis or is a mere marker of damage. In patients who have been treated for cancer, higher levels of GGT may signal ongoing oxidative stress. The role of non-specific inhibitors of GGT such as curcumin is potentially interesting but what we need is a specific non-toxic GGT inhibitor that can be tested in a wider preventive/adjuvant role in selected patients with premalignant changes or established cancer. 


\section{REFERENCES}

Corti A, Duarte TL, Giommarelli C, De Tata V, Paolicchi A, Jones GDD, Pompella A (2008) Membrane gamma-glutamyl transferaseactivity promotes iron-dependent oxidative DNA damage in melanoma cells. Mutat Res Fundam Mol Mech Mutag, doi:10.1016/j.mrfmmm.2009.05.010

Dawson J, Smith GD, Boak J, Peters TJ (1979) $\gamma$-glutamyl transferase in human and mouse breasttumours. Clin Chim Acta 96: 37-42

Fentiman IS, Allen DS (2010) Gamma-glutamyl transferase (GGT) and breast cancer risk. Br J Cancer 103: 90-93

Gallagher CM, Chen JJ, Kovach JS. (2010) Environmental cadmium and breast cancer risk. Aging 2: 804-814

Hanigan MH, Frierson HF, Swanson PE, De Young BR (1999) Altered expression of gamma-Glutamyl transpeptidase in human tumors. Hum Pathol 30: 300-305

Lee D-H, Lim J-S, Song K, Boo Y, Jacobs DR (2006) Graded associations of blood lead and urinary cadmium concentrations with oxidative-stressrelated markers in the U.S. population: results from the Third National Health and Nutrition Examination Survey. Environ Health Perspect 114: 350-354

Orlowski M, Meister A (1970) The $\gamma$-glutamyl cycle: a possible transport system for amino acids. PNAS 67: 1248-1255

Panahi Y, Sahebkar A, Amiri M, Davoudi SM, Beiraghdar F, Hoseininejad SL, Kolovand M (2011) Improvement of sulphur mustard-induced chronic pruritus, quality of life and antioxidant status by curcumin: results of randomised, double-blind, placebo-controlled trial. $\mathrm{Br}$ J Nutr 18: 1-8
Polterauer S, Hofstetter G, Grimm C, Rahhal J, Mailath-Pokorny M, Kohl M, Concin N, Tempfer C, Marth C, Reinthaller A (2011) Relevance of gamma-glutamyl transferase - a marker for apoptotic balance - in predicting tumor stage and prognosis in cervical cancer. Gynecol Oncol 122: $590-594$

Quiroga A, Quiroga PL, Martínez E, Soria EA, Valentich MA (2010) Antibreast cancer activity of curcumin on the human oxidation-resistant cells ZR-75-1 with gamma-glutamyl transpeptidase inhibition. J Exp Ther Oncol 8: 261-266

Ruhl CE, Everhart JE (2009) Elevated serum alanine aminotransferase and $\gamma$-glutamyl transferase and mortality in the United States population. Gastroenterol 136: 477-485

Seebacher V, Polterauer S, Grimm C, Rahhal J, Hofstetter G, Bauer E-M, Husslein H, Leipold H, Marth C, Reinthaller A, Concin NV (2012) Prognostic significance of gamma-glutamyltransferase in patients with endometrial cancer: a multi-centre trial. Br J Cancer 106: 1551-1555

Strasak AM, Pfeiffer RM, Klenk J, Hilbe W, Oberaigner W, Gregory M, Concin H, Diem G, Pfeiffer KP, Ruttmann E, Ulmer H (2008) Prospective study of the association of gamma-glutamyl transferase with cancer incidence in women. Int J Cancer 123: 1902-1906

Van Hemelrijck M, Jassem WI, Walldius G, Fentiman IS, Hammar N, Lambe M, Garmo H, Jungner I, Holmberg L (2011) Gamma-glutamyl transferase and risk of cancer in a cohort of 545460 persons - the Swedish AMORIS study. Eur J Cancer 47: 2033-2041 